\title{
THEORETICAL FrameWORK FOR RESEARCH ON MATHEMATICAL OLYMPIADS IN LATIN AMERICA
}

\author{
Oscar F. Bernal Pedraza \\ Universidad de los Andes, Colombia
}

KEY WORDS

Mathematics contests Mathematics Olympiads Mathematics competitions
ABSTRACT

This theoretical framework is intended to serve as guide to research on national Mathematical Olympiads in Latin America. Research with the goal to elucidate critical factors involved in the existence and results obtained by Latin American teams in the International Mathematical Olympiad (IMO) and other international contests, may find a stepping stone in this framework and the references cited in it. From the way local committees see themselves and their indicators for success to the feedback subsumed in the IMO results, different comparable metrics for success must be developed to understand the specific challenges faced by these organizations and the goals set by themselves and the educational communities in their own countries. As for Latin American countries the IMO is not the only competition they attend or their single metric for success, reference to the IMO is provided as the evolving opportunity leading to the creation of local Olympiad committees, the committees this framework presents as an opportunity for research and understanding of the search for talent in developing countries. As a way of closing the document, a few questions are proposed, offering both quantitative and qualitative research areas and with the possibility to reach findings helpful for those organizations, for the school students in their respective countries, and for similar organizations in other countries. 


\section{Introduction}

$\mathrm{T}$ he Mathematical Olympiad movement grew worldwide at an amazing rate over the last century. In the words of Kenderov (2009), "It would not be an exaggeration to say that the rise and development of Mathematics Competitions is among the characteristic phenomena of the 20th century" (p. 17).

Tracing the history of the International Mathematical Olympiad (IMO) over the last sixty years provides strong proof of that growth. There was no IMO by 1957, although according to Kenderov (2006) the idea of organizing it for the first time was already under discussion; furthermore, there was no "International Mathematical Olympiad" name, as it was first used in 1959 before the first IMO was held (Turner, 1978). By 1967 the IMO was already on its ninth edition, hosted by the former Yugoslavia, with 13 participating countries. A decade later, in 1977, the IMO reached 21 participating countries and by that time 23 countries in total had attended at least once the contest. Ten years later, the 1987 edition hosted by Cuba received 42 participating countries, twice 1977's number and more than three times that of 1967. Jumping forward another decade, Argentina hosted the 1997 IMO with 82 teams in contest, nearly doubling again the number. The 2007 IMO, held in Vietnam, received 93 teams94 according to Kenderov (2009)-, not increasing as much as on the previous decades, but nevertheless, still growing. For the current year, 2017 IMO, hosted by Instituto de Matemática Pura e Aplicada (IMPA) in Rio de Janeiro, Brazil, just announced-June 29ththrough social media, that there are 112 countries registered for the competition, breaking the record set just one year before with 109 participating countries attending the 2016 edition held in Hong Kong (IMO Advisory Board, 2016b; The 58th International Mathematical Olympiad (IMO 2017), 2016). The short review done here shows steady trend for increase in the number of participating countries, with more than half of all world's countries attending in the last few years.

Almost in every case, participating countries in the IMO choose their contestants through a national competition and create associated training sessions to get those contestants ready to carry their country's name to the IMO. The increasing numbers for participating countries in the IMO are simultaneously cause and consequence of an increasing network of local committees organizing mathematics competitions, and in that sense it is proof of the existence of those local committees and their will to be recognized worldwide. The reasons for the importance of those local committees are at the base of this framework, and the critical factors for their success are within the expected outcomes of future research.

\section{Theoretical Framework}

"The International Mathematical Olympiad (IMO) is nowadays the most important and prestigious mathematical competition for high school students" (Berinde \& Pacurar, 2009, p. 15). Those words summarize the way people involved in the Mathematical Olympiad movement see the IMO, and some paraphrasing of them can be found in almost every piece about the contest (Berinde \& Pacurar, 2009; Djukic, Jankovic, Matic, \& Petrovic, 2006; Kenderov, 2006; Turner, 1978; Verhoeff, 2011). Its importance within the community provides support for the use of IMO results as a preliminary indicator of success for those national organizations, and the inclusion of the IMO as a motivating factor for the growth of national Olympiad organizations.

However, the goals for the IMO, and for mathematics contests in general, are beyond the plain competition and the crowning of a winner, it can be said that it goes beyond the participating teams and even the participating countries. As stated in the IMO Regulations (IMO Advisory Board, 2016a)

1.4 The aims of the IMO are:

- to discover, encourage and challenge mathematically gifted young people in all countries.

- to foster friendly international relationships among mathematicians of all countries.

- to create an opportunity for the exchange of information on school syllabuses and practices throughout the world.

- to promote mathematics generally. 
Analyzing these aims, there are three key components to be highlighted: intention for a fully global reach, sense of community, and emphasis on both mathematical talent and knowledge; none of the stated aims point to the contest itself or its results, making competition the vehicle for bigger goals.

Global still a long term goal for the IMO, with 112 participating countries in 2017 still far away from the 193 member states of the UN (United Nations, 2016). However, numbers are impressive from the chronological perspective. According to different sources, the first contemporary mathematical contest was the Eötvös competition beginning in 1894 (Kenderov, 2006, 2009; Turner, 1978; Verhoeff, 2011), and as of December 2016 there were about 130 countries in the IMO database-taking out those countries that no longer exist (IMO Advisory Board, 2016b). On average there was at least one additional country involved in mathematical contests every year. There is no reason to assume there are no mathematical contests under IMO-like formats in countries outside of that list, but taking the IMO as reference 130 is a well-supported estimate, about two-thirds of the countries in the world.

The sense of community in these competitions is addressed from different viewpoints. Verhoeff (2011) makes a case for the value of the IMO proposing as one of the most relevant facets of each year's competition the sense of Community before and after the tests, both between team leaders and between students. Kenderov (2009) provides an historical overview of the first 25 years of the World Federation of National Mathematics Competitions (WFNMC), the organization overseeing the vibrant community forged around the IMO and mathematical contests in general. The WFNMC is so linked to the IMO that their 8th conference will be held right after 2018 IMO (World Federation of National Mathematics Competitions, 2016). The importance of the WFNMC to the international mathematical community is beyond doubt, for example it is recognized by the International Mathematical Union (IMU) as one of the International Commission on Mathematical Instruction (ICMI) Affiliated Study Groups since 1994 (Bass \&
Hodgson, 2004). Another way the community has been created and developed around mathematical contests is through the creation of regional competitions, sometimes considered small communities by themselves (Kenderov, 2006); some of those regional competitions are IMO spin-offs, but some others have developed their own procedures.

Talent search in mathematics is probably at the center of the whole idea of mathematical contests, being the aims of the IMO just an example of that. Campbell and Walberg (2010) include the following as common ground for academic competitions:

All competitions operate under a series of assumptions that constitute a distinctive rationale:

1. Children with talent need to be identified early.

2. Competitions are needed because many schools do not have the differentiated curriculum or the resources that are needed to challenge extraordinary students.

3. Contests will attract participants with extraordinary talent.

4. Contests will motivate the early development of talent.

5. Once developed, this talent is expected to contribute to society. (p. 8)

Furthermore, the community surrounding mathematical contests of this kind traditionally believe on the need to develop young talent, summarized in the phrase "Unlike other natural resources, such as mineral deposits, which remain preserved for the future generations, if undiscovered and unused, the talent of a young person is lost forever, if it is not identified, cultivated, and employed properly" (Kenderov, 2006, p. 1588). This belief places the efforts made by the national mathematics competitions at the service of the development of scientific thinking worldwide through the discovery and nurture of young talents.

Studies on the impact of mathematics competitions, including the IMO, on talent search and development are flattering to their value, to say the least. Campbell (1996) highlights the value of finding talented children at early age and the positive results brought by both the American Mathematical Olympiad and the Westinghouse Talent Search in the United 
States. In subsequent analyses, Campbell and Walberg (2010) also include data from the physics and chemistry Olympiads, and report that the largest percentage of students chose career paths related to their respective Olympiad (mathematics, physics, or chemistry) and the largest percentage of students completing their doctoral studies were former winners of the mathematical Olympiad. Furthermore, Subotnik, Miserandino, and Olszewski-Kubilius (1996) in their conclusion state "Clearly, individuals with special interests or talents in mathematics need to be identified as early as possible and supported and challenged by their teachers throughout their formal school experience" (p. 570), and put special emphasis on the positive effects preparation for the IMO has on achievement and life choices. Finally, Bicknell (2008) speaking about mathematics competitions in a broader sense emphasizes the role of competitions and challenges on helping students develop skills such as self-directed learning and co-operative team work.

This dissection of the aims of the IMO, inherited by most of the local committees in charge of national and regional contests, is also part of the required support for the selection of Latin American national mathematics Olympiads as the subject of study.

\section{Why Latin America?}

Latin American countries have a wide number of characteristics making their case simultaneously special and relevant.

On one hand, together with Spain and Portugal, they make one of the most widely known regional communities in mathematical Olympiads, all around the Iberoamerican Mathematical Olympiad (OIM, acronym from Spanish). The OIM, created in 1985 by the chairpersons of a few local Olympiad committees with special mention to the leadership of Mary Falk de Losada, begun-and still runs-aiming for two main goals: first, to help local committees on providing their best students with opportunities to train and prepare for the IMO; second, to open the space for local committees to share knowledge and experiences allowing them to learn from others. The OIM and the IMO share almost the same official aims and goals as well as a common understanding related to the importance of reach, community, and mathematical talent and knowledge. The following is a translation from Spanish:

The OIM is a competition among young students from Iberoamerican countries, with the aims to:

- To promote the study of mathematics in the Iberoamerican countries.

- To find and encourage young talents in the Iberoamerican countries.

- To sponsor friendly relations among students, professors, and teachers of mathematics in the Iberoamerican countries.

- To create an opportunity for the exchange of educational experiences among mathematics educators from the Iberoamerican countries. (XXXI Olimpiada Iberoamericana de Matemática 2016, 2016)

The OIM quickly got to be the meeting point for national mathematical competition organizations. Less than 10 years after the first OIM was hosted by Colombia, all Iberoamerican countries were, to some extent, involved in the OIM. Countries sometimes did not participate each year due to bureaucratic or budgetary issues. Nevertheless, advances in various forms of communication allowed for close ties even with the absence of some member countries each year.

Almost all Latin American countries participated for the first time in the IMO close to the birth of the OIM. México, Venezuela, and Colombia in 1981; Perú, Panamá, and Nicaragua in 1987; and Argentina and Ecuador in 1988 (IMO Advisory Board, 2016b) are just some examples of that, highlighting the importance of the Mathematical Olympiad community in Latin America. The existence of the OIM as a common ground and its continued work as a practical step for Latin American students to reach the IMO provide reasonable support for comparison as shared data is available. Under the umbrella of the OIM other smaller regional competitions were founded, like the Olimpiada Matemática del Cono Sur and the Olimpiada Matemática de Centroamérica y el Caribe, increasing the availability of stepping stones for talented students in their mathematical development, and at the same time providing new spaces for mathematical Olympiad committees to share their 
experiences and grow together. Also, as part of the OIM and then the regional competitions that found inspiration in it, the OIM included additional activities and prizes to increase both the sense of community and the motivation for students and teams. As one example, a trophy is given for the country with the most progress in the OIM contrasting with the two previous years. As another example, a recreational team game is organized with mathematical content among teams selected from the contestants but not the national teams divided by country.

On the other hand, Latin American Mathematical Olympiads are a heterogeneous set with common aims but different environments. Some of the organizations are under the protection of national Ministries of Education (i.e. Cuba), others are not (i.e. Panamá). Some have the support of their local Mathematical Society (i.e. Brazil and Mexico) while others do not (i.e. Colombia). Some are working under the protection of public universities (i.e. Costa Rica and Panamá), while others belong to private universities (i.e. Colombia). Still others don't have official support from any specific university (i.e. Venezuela), and the largest ones have continued support from a full university network (i.e. Brazil and México). This complex landscape creates room for each organization to have different ways to reach students, different percentages of national secondary students registered, and different indicators to measure their own success. This large set of complex and interrelated variables provides opportunities for a rich array of both quantitative and qualitative studies. As a developing part of the world, it is important for Latin American countries to increase their understanding of commonalities as well as differences in local contexts, as the mathematical competitions have proved to be a way to find young talented students and support them on their path towards successful careers in Science, Technology, Engineering, and Mathematics (Campbell, 1996; Campbell \& Walberg, 2010; Subotnik et al., 1996).

Taking this theoretical framework into account, here are some questions proposed that may lead to research, and that are fully open for discussion and improvement:

Do local mathematical Olympiad committees in Latin American countries consider the search for talented students as one of their aims? And, if so, what is the definition of talent they use to frame their efforts?

To what extent are the IMO goals adopted by the local mathematical Olympiad committees and what changes or adaptations are made to them when becoming local?

Which factors are relevant for the results and possible success of Latin American countries and their local mathematical Olympiad committees when competing in the IMO?

Other than IMO and OIM results, what is considered by Latin American Mathematical Olympiad committees to be indicator of success?

What ways for sharing experiences and knowledge are local committees in Latin America using, other than conversation during the different international competitions available for them? 


\section{References}

Bass, H., \& Hodgson, B. R. (2004). The international commission on mathematical instruction: What? why? for whom? Notices of the American Mathematical Society (51), 639-644. Retrieved Jan 4th, 2017, from http://www.ams.org/notices/200406/comm-bass.pdf

Berinde, V., \& Pacurar, M. (2009, December). The measure of a great idea: 50 years on from the creation of the international mathematical olympiad. European Mathematical Society Newsletter (74), 15-18.

Bicknell, B. (2008). Gifted students and the role of mathematics competitions. Australian Primary Mathematics Classroom, 13(4), 16-20.

Campbell, J. R. (1996). Early identification of mathematics talent has longterm positive consequences for career contributions. International Journal of Educational Research, 25(6), 497-522. Retrieved from $\quad$ http://www.sciencedirect.com/science/article/pii/S0883035597867286 DOI: $10.1016 /$ S0883-0355(97)86728-6

Campbell, J. R., \& Walberg, H. J. (2010). Olympiad studies: Competitions provide alternatives to developing talents that serve national interests. Roeper Review, 33(1), 8-17. DOI: 10.1080/02783193.2011.530202

Djukic, D., Jankovic, V., Matic, I., \& Petrovic, N. (2006). Introduction. In The IMO compendium: A collection of problems suggested for the international mathematical olympiads: 1959-2004 (pp. 1-3). New York, NY: Springer New York. Retrieved from http://dx.doi.org/10.1007/0-387-33430-0 1 DOI: 10.1007/0-387-33430-0 1

IMO Advisory Board. (2016a). General regulations (current version approved at the IMO 2016). Faculty of Mathematics and Physics of the University of Ljubljana. Retrieved Jan 2nd, 2017, from http://www.imo-official.org/documents/RegulationsIM0.pdf

IMO Advisory Board. (2016b). International mathematical olympiad. Faculty of Mathematics and Physics of the University of Ljubljana. Retrieved Jan 2nd, 2017, from http://www.imoofficial.org/default.aspx

Kenderov, P. S. (2006, August). Competitions and mathematics education. In M. Sanz-Solé, J. Soria, J. L. Varona, \& J. Verdera (Eds.), Proceedings of the international congress of mathematicians (pp. 15831598). Madrid.

Kenderov, P. S. (2009). A short history of the world federation of national mathematics competitions. Mathematics Competitions, 22(2), 14-31. Retrieved Jan 5th, 2017, from http://www.wfnmc.org/history.pdf

Subotnik, R. F., Miserandino, A. D., \& Olszewski-Kubilius, P. (1996). Implications of the olympiad studies for the development of mathematical talent in schools. International Journal of Educational Research, 25(6), 563-573. Retrieved from http://www.sciencedirect.com/science/article/pii/S088303559786733X DOI: $10.1016 /$ S0883-0355(97)86733-X

The 58th International Mathematical Olympiad (IMO 2017). (2016). IMO 2017 - 58th international mathematical olympiad. Retrieved Jan 2nd, 2017, from http://www.imo2017.org.br/

Turner, N. D. (1978, December). A historical sketch of the olympiads, national and international. The American Mathematical Monthly, 85(10), 802-807.

United Nations. (2016). Member states / United Nations. Retrieved Jan 4th, 2017, from http://www.un.org/en/member-states/

Verhoeff, T. (2011). De IMO - over talent, plezier en wiskundekringen [The IMO: About talent, fun, and math circles]. Nieuw Archief voor Wiskunde, 5/12(2), 106-108. Retrieved Jan 3nd, 2017, from http://www.nieuwarchief.nl/serie5/pdf/naw5-2011-12-2-106.pdf (A complete translation and adaptation by the author is available in English from http://s3.amazonaws.com/academia.edu.documents/32339268/IMO-paper-NAW-2011-

EN.pdf?AWSAccessKeyId=AKIAJ56TQJRTWSMTNPEA\&Expires=1483416849\&Signature=e9dp5SL xT2fCuBeeAi8mghG70Mc\%3D\&response-content-disposition=inline\%3B\%20filename\%3DThe IMO About Talent Fun and Math Circle.pdf) 
World Federation of National Mathematics Competitions. (2016). WFNMC home page. AMT Publishing. Retrieved Jan 5th, 2017, from http:// www.wfnmc.org/

XXXI Olimpiada Iberoamericana de Matemática $2016 . \quad$ (2016).
31olimpiadaiberoamericana.ucn.cl/reglamento/. Universidad Católica del Norte. Retrieved Jan 5th, 2017, from http://31olimpiadaiberoamericana.ucn.cl/reglamento/ 